\title{
Design of Dual Notch UWBMIMO Antenna with Defected Ground Structure.
}

\author{
${ }^{1}$ J. Prasanth Kumar, D. Nataraj, G. Nikitha Raj, G. Karunakar
}

\begin{abstract}
In this paper A dual band notched MIMO antennais designed with defected ground structure as ground plane and its characteristics are analyzed. The antenna covers $U W B$ frequency ranging from 3.1-10.6 $\mathrm{GHz}$ with single notch band characteristics with maximum gain of $3.7 \mathrm{~dB}$. The antenna provides radiation efficiency of $94 \%$ with front to back to ratio of $64 \%$. The simulated studied is carried for many frequency band applications. The designed antenna shows patterns similar to that of a the dipole. The substrate used to design this antenna is FR4 withdimensions of $26 \mathrm{~mm}$ x40mmx1.6mm and dielectric constant of 4.4.The notch bands are at WLAN and WiMax frequencies.
\end{abstract}

Index Terms: MIMO Antenna, ultra wideband range,defected ground structure, notch band, parametric analysis.

\section{INTRODUCTION}

To perform best quality of services MIMO technique is considered as prominent key. This system can improve the reliability and capacity over single antennas. In designing the MIMO systems requires multiple antennas with less mutual coupling in MIMO systems [1]. MIMO antennas has the capability to ameliorate multipath fading, channel capacity, data rates for wireless applications. Recent advancements UWB technology has gained more attention in short range communication with wide bandwidth, low cost, high data rate [2]. The main limitation in UWB systems is multipath propagation which can be addressed by MIMO systems. The combination of UWB-MIMO can provide better efficiencies in scattering environment with communication operating range and improved channel capacity.

The main attraction of MIMO technology is enhancing the channel capacity and due to limited availability of free spectrum it's difficult to place antenna with low isolation. The the compact MIMO antenna with high isolation consists of meandering monopoles [3]. To reduce the isolation inverted $\mathrm{T}$ - shaped slot are etched on the ground structure and meandering structures on patch. The low-profile antenna foe multiband applications are designed with mending loops for mobile phone applications [4].

The MIMO antenna is designed and presented with inverted F-shape antenna with slot-based frequency agile antennas for dual band applications. The MIMO antenna with notch band UWB antenna is designed with two identical elements [5]. In

Revised Manuscript Received on December 13, 2019.

J Prasanth Kumar, ECE Department, Ramachandra College of Engg, Eluru, A.P.,India.

D.Nataraj, ECE Department, Pragathi College/ Pragathi College, Kakinada, A.P., India.

G. Nikitha RajECE Department, GITAM (Deemed to be University), Visakhapatnam,, A.P., India.

Dr. G. Karunakar, ECE Department,GITAM (Deemed to be University), Visakhapatnam, A.P., India. the back side of the ground structure rhombic structure is used. Usually the orthogonally feed MIMO antenna achieves polarisation diversity and very high isolation [6]. A compact broad band antenna for dual polarised applications is designed with cavity backed Bowtie antenna in conjunction with parasitic elements [7].

The Quad element MIMO antenna is designed with T-shaped stub and CSRR. the antenna is designed to cover many frequency applications like ISM/Bluetooth (2.4-2.45) and LTE (2.3-2.4) WiMAX (5.25-5.58) and K-band (7.2-8.39) applications. The triple notch band antenna is designed to WiMAX and WLAN frequencies [8]. Mushroom shaped electromagnetic band is used to attain the notch bands. To minimize the mutual coupling radiating elements are separated by with stepped structure.

The compact UWB MIMO antenna is designed with inverted U-shaped slots to notch WLAN bands in operating frequency bands. Dual port MIMO antenna is designed for band rejection facility [9]. To achieve the notching rectangular shaped elements are chosen and stepped stub is added and envelope correction coefficient of 0.013 and capacity loss of 0.35 is achieved. Tapered fed compact UWB antenna is designed dual band notch characteristic and mutual coupling of $-22 \mathrm{~dB}$ is obtained over operating band [10].

\section{ANTENNA DESIGN}

\section{A. Antenna Design Approach}

The MIMO antenna with dimensions of $26 \mathrm{~mm} \times 40 \mathrm{~mm}$ is designed on FR-4 epoxy substrate material with dielectric constant of 4.4 and having a thickness of $1.6 \mathrm{~mm}$.the antenna is feed by $50 \mathrm{ohm}$ microstrip line. the basic antenna is designed with rectangular patch.in the modified structure antenna is feed by triangular shape on the rectangular patch antenna. The width of the antenna is given by the equation

$$
W \leq \frac{c}{2 f r}\left(\in r+\frac{1}{2}\right)-\frac{1}{2}
$$

The effective dielectric constant of the substrate is given

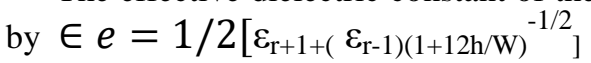

The length of the patch is given by

$$
\mathrm{L}=\frac{c}{2 f r} \sqrt{ } \varepsilon_{\mathrm{e}}{ }^{-} 2 \Delta \mathrm{L}
$$

Length of the $\mathrm{U}$ shaped Stubfor notch band is given by the eqn1 $L_{N}=\frac{c}{2 f N \sqrt{\epsilon} \text { eff }} \approx \frac{\lambda}{2}$

In ground structure radiating stubs are added. And this stub is placed between the two defected grounds as shown in Fig 1. the analysis has been done for the antenna and sequentially discussed and table of parameters regarding the model has been demonstrated.

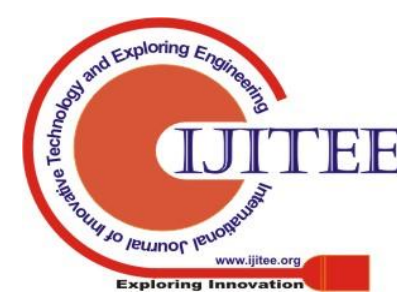




\section{Design of Dual Notch UWBMIMO Antenna with Defected Ground Structure.}

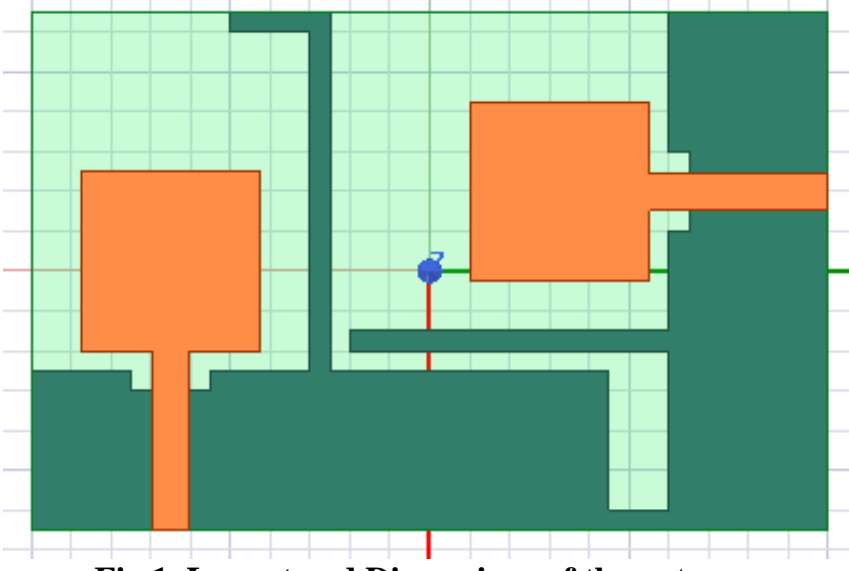

Fig 1. Layout and Dimensions of the antenna

Table 1. Dimensions of the the antenna

\begin{tabular}{|l|l|l|l|}
\hline W & $40 \mathrm{~mm}$ & A & $1 \mathrm{~mm}$ \\
\hline L & $26 \mathrm{~mm}$ & B & $4 \mathrm{~mm}$ \\
\hline WF & $1.8 \mathrm{~mm}$ & C & $1 \mathrm{~mm}$ \\
\hline LF & $9 \mathrm{~mm}$ & S1 & $4 \mathrm{~mm}$ \\
\hline LG & $8 \mathrm{~mm}$ & S2 & $1 \mathrm{~mm}$ \\
\hline WG & $31 \mathrm{~mm}$ & ST1 & $3 \mathrm{~mm}$ \\
\hline H & $1.6 \mathrm{~mm}$ & ST2 & $3 \mathrm{~mm}$ \\
\hline
\end{tabular}

The above table represents the dimensions of the the antenna.

\section{RESULTS AND DISCUSSION}

The basic structure consists of two rectangular patches placed orthogonally and the antenna operates in UWB frequency range. In the Fig .2a it represents that the antenna operates from $3 \mathrm{GHz}$ to $10 \mathrm{GHz}$ and with two notch bands.In Fig $2 \mathrm{~b}$ represents S-Parameters of the antenna which covers the frequencies from $2.1 \mathrm{GHz}$ to $12.7 \mathrm{GHz}$. In the ground structure the stubs are loaded in the ground structure which helps in the to get the band notch characteristics.

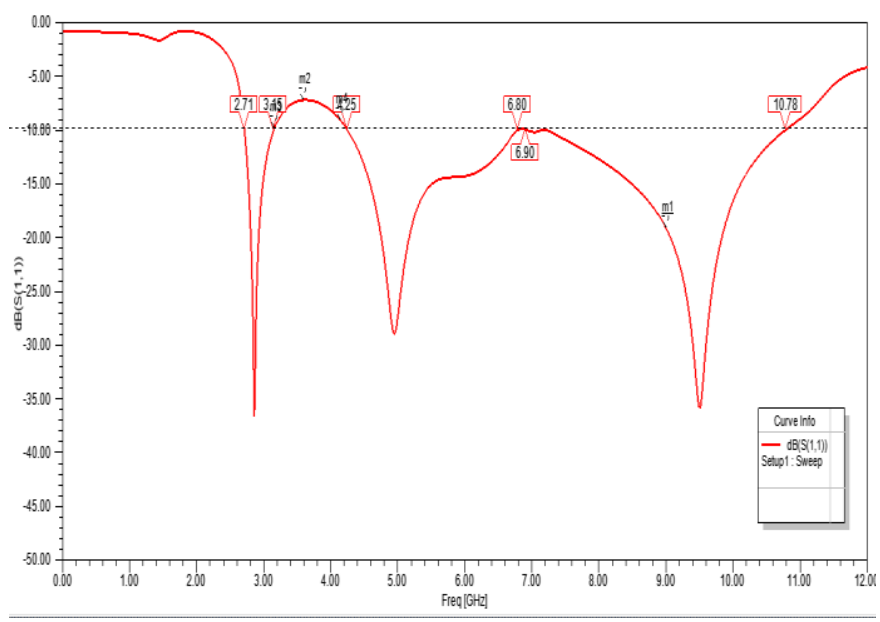

Fig 2a. S parameters results of antenna

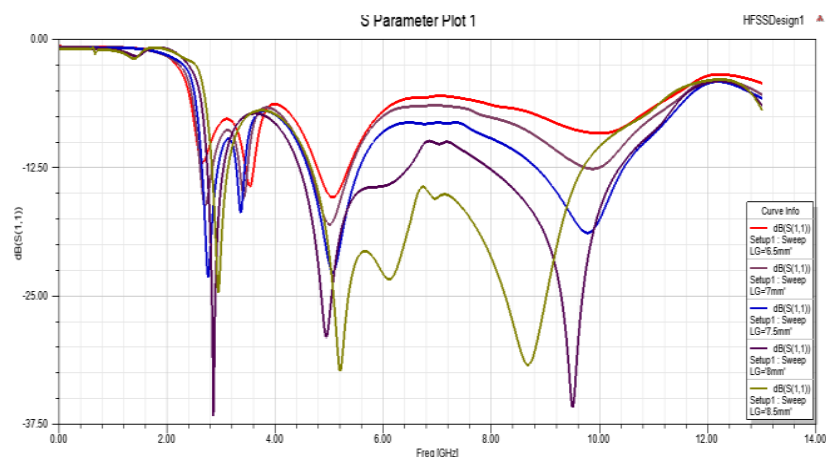

Fig 2b. S parameters curve of the antenna

The rejection band of the antenna ranges from $3 \mathrm{GHz}$ to $4.1 \mathrm{GHz}$. In the fig 2 the isolation losses are also presented. The antenna covers almost all applications frequencies that are suitable for wireless communication applications.

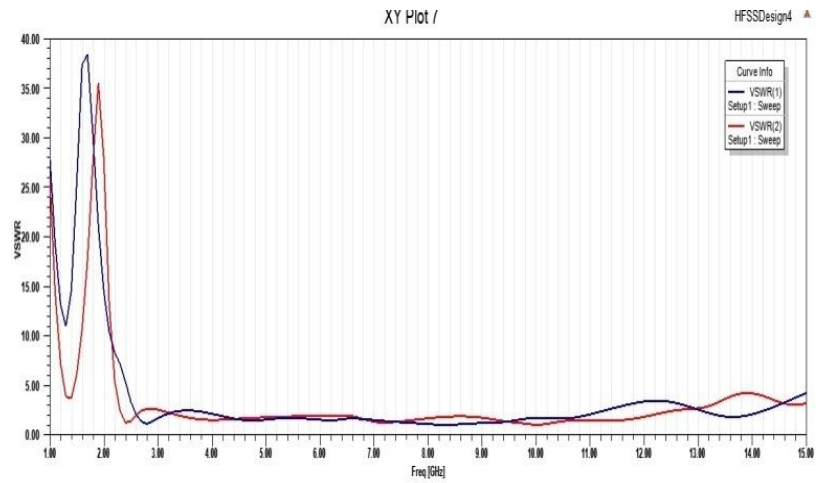

Fig 3. VSWR of the antenna

Fig 3 indicates the VSWR for the antenna the observed values of the antenna shows VSWR below than 2 at the operating frequency range.

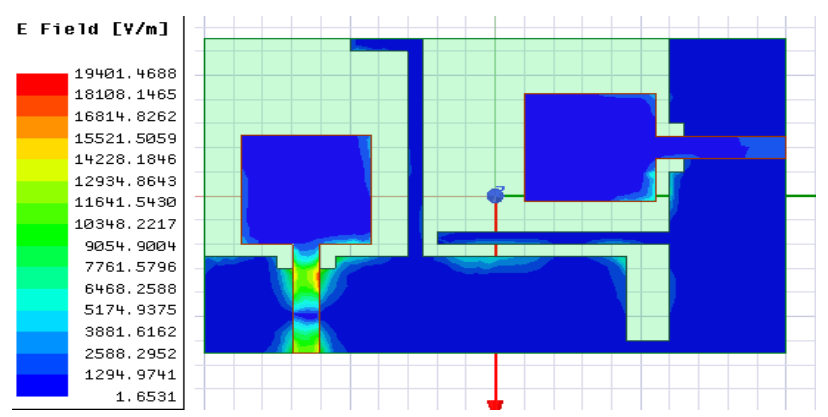

(a)

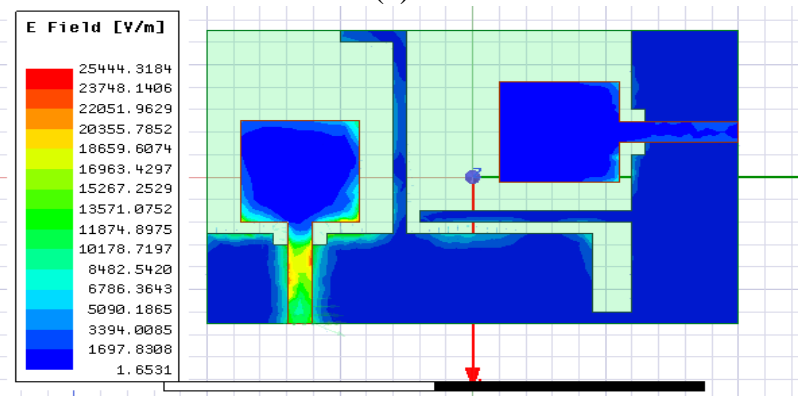

(b)Fig 4. E-field of an antenna at 5GHz(a) PORT-2,

(B) PORT-1

Published By:

Blue Eyes Intelligence Engineering

\& Sciences Publication 
Fig.4 shows the e-field pattern antenna most of the E-field is distributed along the feedline and the edges of the patch antenna in this case study individual antennas are excited and analyzed the performance.

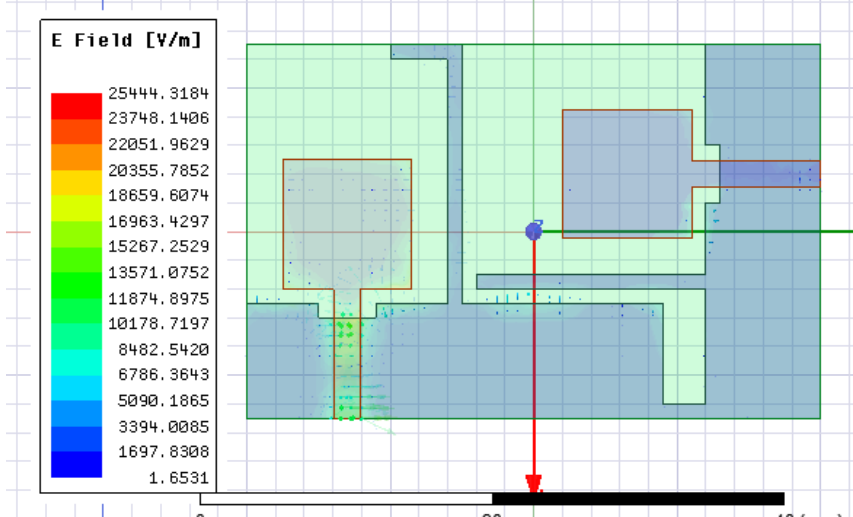

(a)

Fig 5a \& b represents the current distributions of the the antenna are presented. In this analysis two cases are studied by exciting the individual antennas. In this case maximum intensity of red color is observed at the feed line and corners of radiating patch and in the edges of the ground structure.

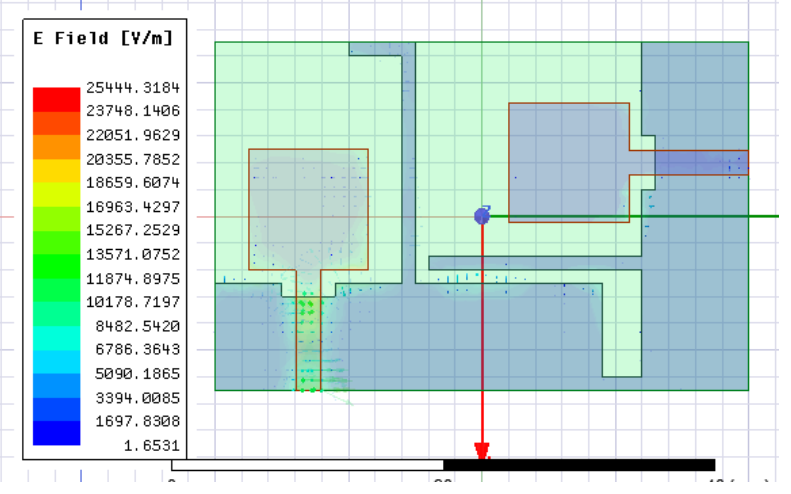

(b)

Fig 5: current distribution of the antenna at $5 \mathrm{GHz}$
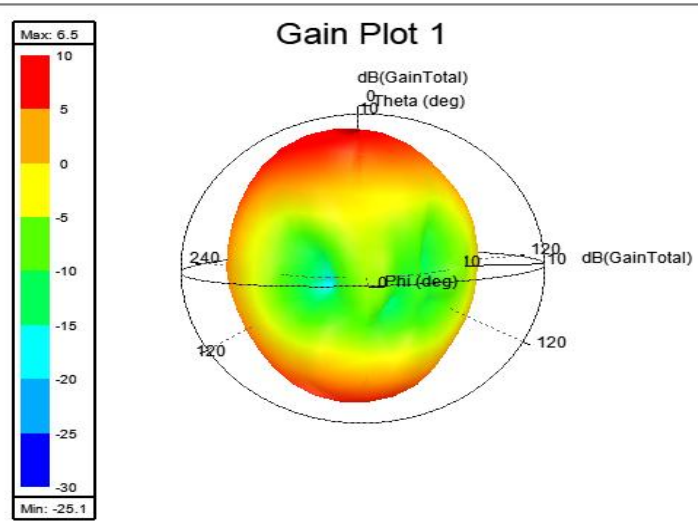

Fig 6. Gain of the antenna

Fig 6. represents gain of the the antenna at constant gain of about $3.7 \mathrm{~dB} 5.5 \mathrm{GHz}$ with a peak gain of $6.5 \mathrm{db}$. In the fig 7 the radiation patterns of the antenna are presented with representation of co and cross polarization levels. The antenna shows the bidirectional and omni directional radiation patterns. In the Fig 7 (c) and (d) represents the notch frequency characteristics of the antenna in all the figures the red colored lines represent the orientation towards E-plane and other color as the H-plane. In Fig 7(a) represents that a dipole type of radiation patterns at fig 7 (b) a slight variation in the orientation of the H-plane changes has been noticed under the notch band fig 7(c) and (d) shows the copolarization and cross polarization at working frequency and notch bands are observed. bands some Fig 8 represents the peak gain the antenna which shoes the maximum peak gain of $5.5 \mathrm{Db}$ at $9.8 \mathrm{GHz}$

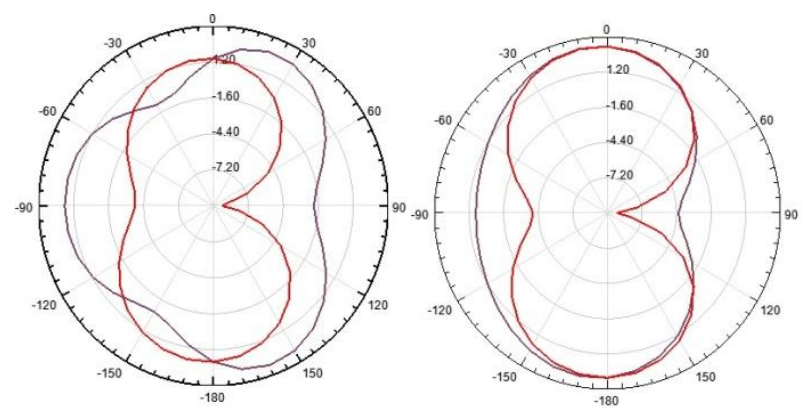

(a) at $5 \mathrm{GHz}$

(b) at $3.5 \mathrm{GHz}$

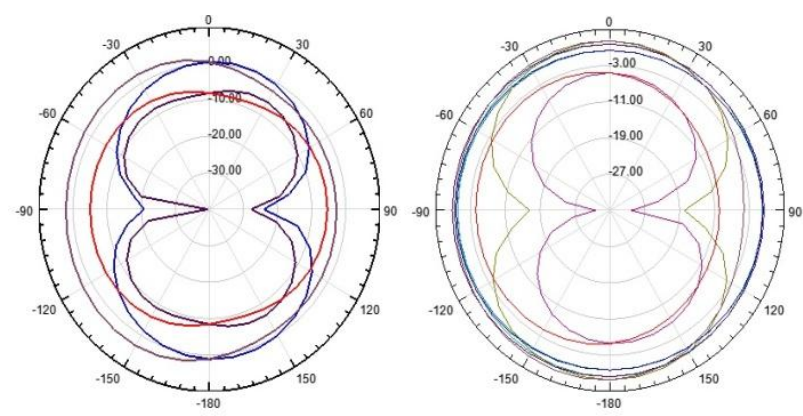

(C) at $5 \mathrm{GHZ}$

(d) at $3.5 \mathrm{GHz}$

Fig 7. Radiation patterns and co and cross polarization of the antenna at working band (a) and (c)5GHz and at notch band (b) $5 \mathrm{GHz}$ (d) $3.5 \mathrm{GHz}$

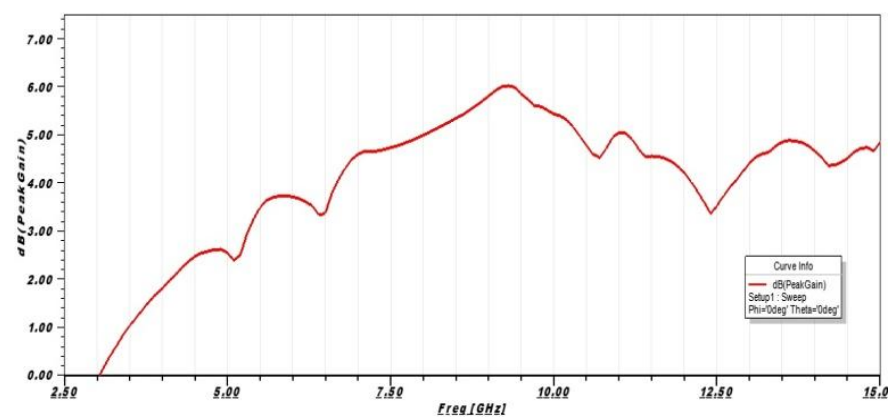

Fig 8: Gain vs frequency of the antenna

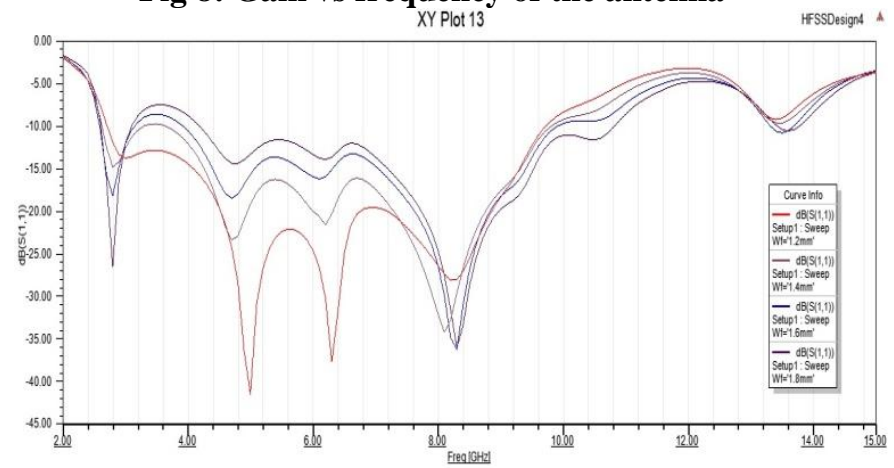

Fig 9. parametric study by changing width of the feedline

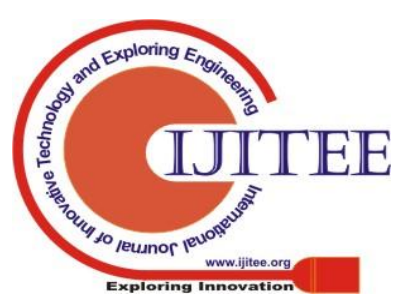




\section{Design of Dual Notch UWBMIMO Antenna with Defected Ground Structure.}

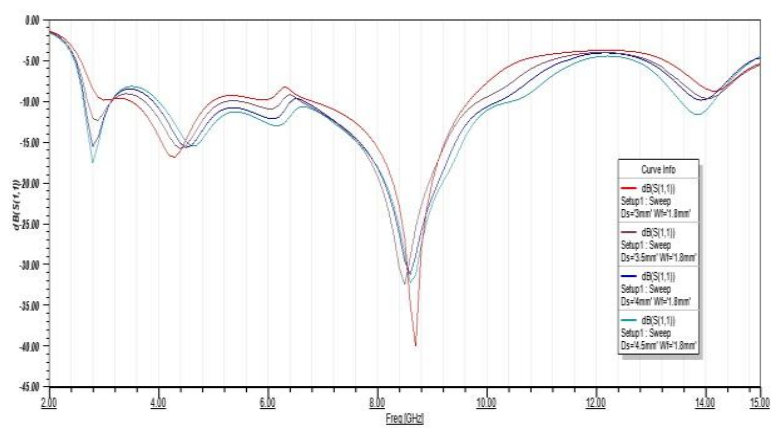

Fig 10. Parametric study by changing the radiating $\operatorname{stub}(\mathrm{Ds})$

To obtain the optimized antenna parameters the antenna studied using the parametric analysis which is represented in the Fig 9 and Fig 10. The analysis is studied by varying the width of the feed and the radiating stub. With change in the dimensions of the antenna the antenna shows the wide band characteristics show enhance by reducing the size and with changing the radiating stub the best output can be observed at dimension that is at $5 \mathrm{~mm}$.

Table.2 Comparison of proposed model with existing literature

\begin{tabular}{|c|c|c|c|c|c|}
\hline $\begin{array}{c}\text { REFEREN } \\
\text { CE }\end{array}$ & $\begin{array}{l}\text { Dimensi } \\
\text { ons }\end{array}$ & $\begin{array}{l}\text { Operati } \\
\text { ng } \\
\text { Frequen } \\
\text { cy }\end{array}$ & $\begin{array}{c}\text { Ban } \\
\text { ds }\end{array}$ & $\begin{array}{c}\text { Isolati } \\
\text { on }\end{array}$ & $\mathrm{ECC}$ \\
\hline [1] & $\begin{array}{c}80 \times 40 \times \\
1.6 \\
\end{array}$ & $\begin{array}{c}2.4-2.6 \\
5.2-6\end{array}$ & Dual & 15 & 0.01 \\
\hline [3] & $\begin{array}{c}90 \times 40 \times \\
1.6\end{array}$ & $\begin{array}{l}2.1-2.7 \\
5.1-6.1\end{array}$ & Dual & 15 & $\begin{array}{c}0.00 \\
23\end{array}$ \\
\hline [5] & $\begin{array}{c}42 \times 62 \times \\
1.6\end{array}$ & $\begin{array}{c}2.38-2.5 \\
2 \\
3.19-6.4 \\
4\end{array}$ & Dual & 10 & 0.02 \\
\hline [7] & $\begin{array}{c}70 \times 90 \times \\
0.8\end{array}$ & $2.4 / 5.2$ & Dual & 33 & $\begin{array}{c}0.01 \\
6\end{array}$ \\
\hline [9] & $\begin{array}{c}70 \times 40 \times \\
0.8\end{array}$ & $2.4 / 5.8$ & Dual & 20 & 0.01 \\
\hline [12] & $\begin{array}{c}40 \times 20 \times \\
1.6\end{array}$ & $\begin{array}{c}2.4-2.5 \\
4.9-5.75\end{array}$ & Dual & 15 & - \\
\hline [13] & $\begin{array}{c}52 \times 75 \times \\
1.6\end{array}$ & $\begin{array}{c}2.4-2.48 \\
5.15-5.8 \\
5\end{array}$ & Dual & 15 & 0.03 \\
\hline $\begin{array}{l}\text { Proposed } \\
\text { work }\end{array}$ & $\begin{array}{c}26 \times 40 \times \\
1.6\end{array}$ & $\begin{array}{c}1.7-1.87 \\
2.45-4.1 \\
5 \\
9.62-11 . \\
16 \\
\end{array}$ & Dual & 10 & $\begin{array}{c}<0.0 \\
5\end{array}$ \\
\hline
\end{tabular}

\section{CONCLUSION}

The antenna is designed for UWB applications with attached stubs in the ground structure antenna shows the notch band characteristics. The designed antenna having good isolation characteristics at the notch band. The antenna provides the impedance bandwidth of $130 \%$ at the operating range of the antenna. the observed values antenna is suitable for wide number of frequency band application.

\section{FUTURE SCOPE}

The mimo antenna with attached stubs in the ground structure shows the notch band characteristics. The designed antenna having good isolation characteristics at the notch band. The antenna provides the impedance bandwidth of $130 \%$ at the operating range of the antenna. the observed valuesantenna is suitable for wide number of frequency band application.

\section{ACKNOWLEDGMENT}

The author thank GITAM deemed to be university for providing this opportunity to do research work in this area

\section{REFERENCES}

1. Dang, J., Li, J., Zhao, L., \& L. Guo,. (2017). A dual-band inverted-F MIMO antnna with enhanced isolationWLAN applications. IEEE Antennas and Wireless Propagation Letters, 16, 2270-2273.

2. S Fernandez, \&S.K. Sharma, (2014). Multiband printed mendered loop antennas with MIMO implementations for wireless routers. IEEE Antens and Wireless Propagation Letters, 96-99.

3. Hussain, R., Khan, M. U., \&Sharawi, M. S. (2018). An Integrated Dual MIMO Antenna System With Dual-Function GND-Plane Frequency-Agile Antenna. IEEE Antennas and Wireless Propagation Letters, 17(1), 142-145.

4. L Kang., H, Li, Wang, X., \& X.Shi, (2015). Compact microstrip-fedoffset MIMO antenna for notched band UWB applications. IEEE Antens and Wireless Propagation Letters.

5. Lee, H., \& Lee, B. (2016). Compact broadband dual-polarized antenna for indor MIMO wireless commnication systems. IEEE Transactions on Antennas and Propagation, 64, 766-770.

6. Yang, Y., Chu, \& Mao, C. (2016). Multiband MIMO antenna for GSM, DGS, and LTE indoor applications. IEEE Antennas and Wireless Propagation Letters, 15, 1573-1576.

7. Zhang, S., \& Pedersen, G. F. (2016). Mutual coupling reduction for UWB MIMO antennas with a wideband neutralization line. IEEE antennas and wireless propagation letters, 15, 166-169.

8. D.Nataraj, Dr.G.Karunakar "Four Element Miniaturized Microstrip Antenna Array using Defected Ground Structure for Satellite Applications" Journal of Web Engineering, Vol. 18, No 4 (2019) 5014 $-5019$

9. Kumar JP, Karunakar G. "Compact C-shaped MIMO diversity antenna for quad band applications with hexagonal stub for isolation improvement”. Int. J RF Microw Comput AidedEng.2019;e21971. ttps://doi.org/10.1002/mmce.21971.

\section{AUTHOR PROFILE}

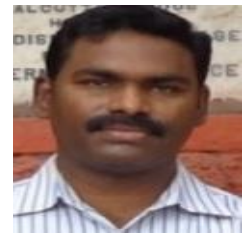

J Prasanth Kumar received BE in Electronics and Communication Engineering from University of Madras and M.Tech specialization in Microwave Engineering from Acharya Nagarjuna University, Guntur. He is currently pursuing his $\mathrm{PhD}$ in Micro strip Antennas from Department of ECE, GITAM Institute of Technology, GITAM Deemed to be University, Visakhapatnam, AP. He produced 10 publications in microstrip antenna and interested research topics are ultra wide band antennas, MIMO antennas, gain, and bandwidth enhancement in broadband and wideband Antennas using DGS structures and FSS Techniques. He is also member of IETE,IEANGandISRD.

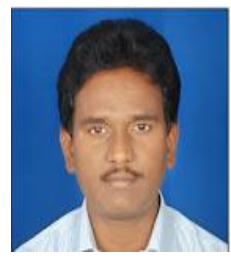

D.Nataraj completed his Master of Engineering in the stream of ECE. (Digital System and Computer Electronic) in the year 2009 from JNTU Hyd. College of Engg. JNTUH. He is working as Assoc. professor in Pragati Engineering College (A), Kakinada India.He is currently pursuing his $\mathrm{PhD}$ in Micro strip

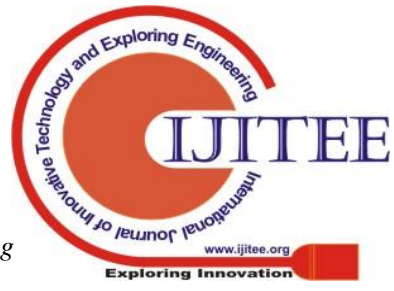


Antennas from Department of ECE, GITAM Institute of Technology, GITAM Deemed to be University, Visakhapatnam, AP.11publications in microstrip antenna and interested research topics are ultra wide band antennas, MIMO antennas, gain, and bandwidth enhancement in broadband and wideband Antennas using DGS structures and FSS Techniques. He is the Life member of IETE.
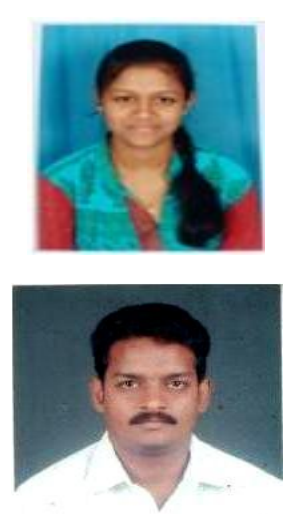

G. Nikitha Raj studing B.Tech final year with CGPA 8.95 in the department of E.C.E, Gitam Institute of Technology, GITAM (Deemed to be University),Visakhapatnam.

Dr. G.Karunakar completed his B.E. and Master of Engineering in the stream of Microwave and Radar engineering in the year of 1996, 1999 respectively. He obtained his Ph.D from Andhra University in 2011. Now, he is working as Associate

Professor in GITAM Institute of

Technology GITAMDeemed to be University, Visakhapatnam, India. He has more than 15 years Teaching \& Research Experience. His area of interests is Antenna and propagation, Microwave and Radars. 